University of Nebraska - Lincoln

DigitalCommons@University of Nebraska - Lincoln

\title{
Effects of a Prereading Intervention on the Literacy and Social Skills of Children
}

\author{
J. Ron Nelson \\ University of Nebraska - Lincoln, rnelson8@unl.edu \\ Scott A. Stage \\ University of Washington, scott_stage@ncsu.edu \\ Michael H. Epstein \\ University of Nebraska - Lincoln, mepstein1@unl.edu \\ Corey D. Pierce \\ Southern Illinois University, Corey.Pierce@unco.edu
}

Follow this and additional works at: https://digitalcommons.unl.edu/specedfacpub

Part of the Special Education and Teaching Commons

\begin{abstract}
Nelson, J. Ron; Stage, Scott A.; Epstein, Michael H.; and Pierce, Corey D., "Effects of a Prereading Intervention on the Literacy and Social Skills of Children" (2005). Special Education and Communication Disorders Faculty Publications. 33.

https://digitalcommons.unl.edu/specedfacpub/33
\end{abstract}

This Article is brought to you for free and open access by the Department of Special Education and Communication Disorders at DigitalCommons@University of Nebraska - Lincoln. It has been accepted for inclusion in Special Education and Communication Disorders Faculty Publications by an authorized administrator of DigitalCommons@University of Nebraska - Lincoln. 


\title{
Effects of a Prereading Intervention on the Literacy and Social Skills of Children
}

\author{
J. RON NELSON \\ University of Nebraska, Lincoln \\ SCOTT A. STAGE \\ University of Washington \\ MICHAEL H. EPSTEIN \\ University of Nebraska, Lincoln \\ COREY D. PIERCE \\ Southern Illinois University
}

ABSTRACT: This study investigated the effects of an intensive prereading intervention on the beginning reading skills and social behavior of kindergarten children at risk for behavioral disorders and reading difficulties. Children identified through a systematic screening process were assigned randomly to experimental or nonspecific treatment conditions. Children who received the intensive prereading intervention showed statistically and educationally significant gains in their beginning reading skills relative to their counterparts in the nonspecific treatment condition. In contrast, improvements in teacher ratings of the classroom competence, emotional and behavioral self-control, and self-confidence of children in the experimental and nonspecific treatment conditions were not statistically significant from one another.

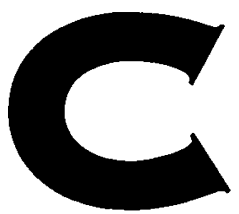

hildren with behavioral disorders (BD) consistently show moderate to severe academic achievement deficits relative to normally achieving students (e.g., Greenbaum et al., 1996; Mattison, Spitznagel, \& Felix, 1998; Meadows, Neel, Scott, \& Parker, 1994; Nelson, Benner, Lane, \& Smith, 2004; Wagner, 1995). Scruggs and Mastropieri (1986), for example, found that a sample of sec- ond-grade children with BD performed one or more standard deviations below normally achieving peers in vocabulary, listening comprehension, spelling, social studies, and science. Children with $\mathrm{BD}$ also appear to have more severe academic achievement deficits than those with learning disabilities (Epstein \& Cullinan, 1983; Gajar, 1979; Scruggs \& Mastropieri, 1986; Wagner, 1995; Wilson, Cone, Bradley, \& Reese, 1986). Furthermore, the results from a longitudinal 
study suggest that $\mathrm{BD}$ may have a more adverse impact on academic achievement over time than do learning disabilities. Anderson, Kutash, \& Duchnowski (2001) reported that children with BD failed to show improvements in their literacy skills from the first to fifth grades, whereas children with learning disabilities showed statistically significant improvements.

Two reviews of the literature on learner characteristics that influence the treatment effectiveness of early literacy interventions provide converging evidence to support the notion that BD has an adverse impact on academic achievement (Al Otaiba \& Fuchs, 2002; Nelson, Benner, \& Gonzalez, 2003). A meta-analytic review (Nelson et al., 2003) indicated that the primary learner characteristics that predict treatment effectiveness of literacy interventions were rapid automatic naming $\left(Z_{r}=.51\right)$, problem behavior $\left(Z_{r}=\right.$ .46), phonological awareness $\left(Z_{r}=.42\right)$, word reading $\left(Z_{r}=.35\right)$, memory $\left(Z_{r}=.31\right)$, IQ $\left(Z_{r}=\right.$ .26) and demographics $\left(Z_{r}=.07\right)$. Furthermore, the negative influence of problem behavior on the treatment effectiveness of literacy interventions was statistically equivalent to rapid automatic naming, phonological, and word reading deficits.

More directly relevant to the current study is research investigating the collateral effects of literacy interventions on the beginning reading skills and social behavior of children with (Falk \& Wehby, 2001) or at risk for BD (Lane, 1999; Lane, O'Shaughnessy, Lambros, Gresham, \& Beebe-Frankenberger, 2001; Lane, et al., 2002). Researchers also have studied the potential collateral effects of literacy interventions on children's social behavior. Such interventions are more likely both to improve a child's repertoire of prosocial skills (e.g., communication skills) essential for classroom functioning and to increase opportunities for positive reinforcement from teachers and peers than other achievement areas such as mathematics (McEvoy \& Welker, 2000).

The results of research exploring the collateral effects of literacy interventions on the social behavior of children with or at risk for $\mathrm{BD}$ are mixed. Lane (1999) investigated the relative effects of literacy and social skills interventions on the beginning reading and social behavior of 53 first-grade children at risk for BD. Six classrooms were randomly assigned to one of three condi- tions: reading (i.e., Phonological Awareness Training for Reading, Torgesen \& Bryant, 1994), social skills (i.e., Social Skills Intervention Guide: Practical Strategies for Social Skills Training; Elliott \& Gresham, 1991), or control. Although children receiving the literacy intervention showed statistically significant improvement in their phonological awareness skills compared to children in the social skills and control conditions, they did not

\section{Behavior disorders may have a more ad- verse impact on academic achievement over time than do learning disabilities.}

show improvement on a measure of word attack skills. Children, regardless of condition, showed no improvements in their social behavior. In contrast, Lane et al. (2002) used a single-case design to assess the effects of a supplementary literacy program (John Shefelbine's Phonics Chapter Books; Shefelbine, 1998) on the beginning reading skills and social behavior of seven children at risk for $\mathrm{BD}$ and reading difficulties. All of the participants generally showed improvements in their beginning reading skills and social behavior. Methodological difficulties (e.g., poorly specified interventions, failure to assess treatment fidelity) have hindered attempts to ascertain the collateral effects of literacy interventions on the beginning reading skills and social behavior of children with or at risk for BD (McEvoy \& Welker, 2000).

This study directly contributes to the investigation of the collateral effects of literacy interventions on the beginning reading skills and social behavior of children at risk for BD. The study uses an empirically validated, cohesive (i.e., theory-driven, specified scope and sequence, standardized set of instructional procedures), intensive prereading intervention (Stepping Stones to Literacy; Nelson, Cooper, \& Gonzalez, 2004) that has produced statistically and educationally significant changes in the beginning reading skills of kindergarten children at risk for $\mathrm{BD}$ and reading difficulties (Nelson, Benner, \& Gonzalez, 2005). With few exceptions (e.g., Lane et al., 2002), interventions used in previous studies with children 
with or at risk for BD generally failed to produce consistent and substantial changes in children's beginning reading skills.

The current study also extends the program of research on the effects of prereading interventions in three ways. First, participants were kindergarten children at risk for BD and reading difficulties. Children with these characteristics may be the least likely to respond to ordinarily effective prereading and reading interventions (Al Otaiba \& Fuchs, 2002; Nelson et al., 2003; Torgesen et al., 1999). Second, the prereading intervention used in the present study focuses exclusively on pivotal early literacy skills (e.g., letter knowledge, phonemic awareness) and does not include word reading skills (e.g., letter-sound correspondence). Previous research on prereading interventions conducted with kindergarten children typically included word reading instructional activities (Jenkins \& O'Connor, 2002). Finally, the prereading intervention included embedded instructional activities to enhance children's rapid automatic naming or serial processing skills (i.e., ability to name serially presented stimuli quickly). Berninger, Abbott, Billingsley, \& Nagy reviewed the literature on serial rapid automatic naming or serial processing deficits and concluded that they should be taken as seriously as phonological deficits (Berninger, Abbott, Billingsley, \& Nagy, 2001). Furthermore, some researchers contend that serial rapid automatic naming and reading involve common processes such as quick access of visual-verbal associations (Cutting \& Denckla, 2001) and acquisition of orthographic knowledge (Wolf \& Bowers, 1999).

This study investigated the effects of an intensive prereading intervention on the beginning reading skills and social behavior of kindergarten children at risk for BD and reading difficulties. The two primary interrelated research questions addressed by the study included:

- What are the effects of an intensive literacy intervention on the beginning reading skills of kindergarten children at risk for $\mathrm{BD}$ and reading difficulties?

- What are the effects of an intensive literacy intervention on the social behavior of kindergarten children at risk for $\mathrm{BD}$ and reading difficulties?

\section{METHOD}

\section{PARTICIPANTS}

A total of 63 selected kindergarten children at risk for $\mathrm{BD}$ and reading difficulties participated over the course of the assessment period. Parental informed consent was obtained in all cases; our approved Institutional Review Board procedures did not require that we obtain child assent. The children were drawn from 27 kindergarten classrooms in 10 elementary schools in the Midwest. A three-step screening process was used to identify participants. The first two steps of the screening process included the first and second gates of the Early Screening Project (ESP; Walker, Severson, \& Feil, 1995) and were used to identify children at risk for $\mathrm{BD}$. The remaining step included the administration of the Dynamic Indicators of Basic Early Literacy Skills (DIBELS) Letter Naming (LNF) probe (Good \& Kaminski, 2002) and was used to identify children at risk of reading difficulties.

We selected a smaller sample $(n=20)$ of children for the nonspecific treatment condition to increase the palatability of our randomization procedures to the participating schools. We anticipated that a sample of this size would be sufficient to equate the preintervention literacy and social behavior levels of children in the experimental and nonspecific treatment conditions and provide sufficient power to detect main effects for the intervention. Forty-seven ( $27 \%$ attrition rate) and 16 (20\% attrition rate) children in the experimental and nonspecific treatment groups participated over the course of the assessment period, respectively.

The screening procedure was conducted at the participating schools during the fifth or sixth week of the school year. At Step 1, teachers were provided with a definition and examples of externalizing and internalizing behavioral characteristics articulated in the ESP. Teachers then generated two mutually exclusive lists of children. The first list included those children whose characteristic behavior patterns most closely resembled the externalizing behavior description. Teachers then rank ordered these children according to the degree to which their behavior matched the externalizing definition. To generate the sec- 
ond list, an identical procedure was followed to list and rank order children according to the internalizing behavior definition.

At Step 2, teachers completed the three ESP scales (i.e., Critical Events Index, Maladaptive Behavior, Adaptive Behavior) on the five highest externalizing and internalizing children identified in the first step. The Critical Events Index has 16 items (e.g., steals, sets fires) that teachers identify as occurring or not occurring. The Adaptive Behavior scale includes 8 items that assess teacher- and peer-related adaptive behavior. The Maladaptive Behavior scale includes 9 items that assesses teacher- and peer-related problem behavior. Teacher ratings on the Adaptive Behavior and Maladaptive Behavior scales are based on the frequency of children's behavior within the past 30 days. Children with $t$ scores of 60 or more on the Critical Events Index, Adaptive Behavior scale, and/or Maladaptive Behavior scales were eligible for participation.

At Step 3, children meeting normative criteria for $\mathrm{BD}$ were assessed using the DIBELS LNF probe (Good \& Kaminski, 2002), which measures the speed with which a child can name letters. Each child was presented with a page of random upper- and lower-case letters and was asked to name as many letters as he or she could in 1 minute. The score was the total number of letters named correctly in 1 minute. Children who identified seven letters or fewer were eligible for participation. These criteria were based on predictive research indicating that children who identified seven or fewer letter names correctly in 1 minute were at high risk for reading difficulties (Jenkins \& O'Conner, 2002).

Participant demographic characteristics (i.e., gender, race, lunch status, age) and ESP Critical Events Index, Adaptive, and Maladaptive $t$ scores are presented in Table 1 . The average age of children was 5.2 years $(S D=0.41)$. A majority of the children selected for participation were males $(75 \%)$. The overall ethnic breakdown included 47 Caucasians, 9 African Americans, 6 Hispanics, and 1 Asian American. Approximately $44 \%$ of the children qualified for free and/or reduced lunch. Chi-square analyses with Yates correction on these nominal data showed no effects for treatment condition: Gender $\left(\chi^{2}(1)=0.002\right.$, $p=.966)$, Race $\left(\chi^{2}(3)=0.88, p=.912\right)$, and Lunch Status $\left(\chi^{2}(1)=0.127, p=.722\right)$.

The overall mean preintervention Critical Events Index, Maladaptive Behavior, and Adaptive Behavior $t$ scores of children were $55.1(S D=$ $6.5), 67.2(S D=9.9)$, and $66.3(S D=7.8)$, respectively. The results of a Condition (Experimental, Nonspecific Treatment) X Gender (Male, Female) Multivariate Analysis of Variance (MANOVA) indicated that there were statistically significant differences in the mean preintervention Critical Events Index, Maladaptive Behavior, and/or Adaptive Behavior $t$ scores of children in the experimental and nonspecific treatment conditions $(F(3,57)=.51, p=.008)$, but not in the case of boys and girls $(F(3,57)=1.19, p=.019)$. Post-hoc analyses showed that the mean Critical Events Index $t$ scores of children in the experimental condition were higher relative to those in the nonspecific treatment condition. The Maladaptive Behavior $t$ scores of children in the nonspecific treatment condition were higher than those of children in the experimental condition. Additionally, the condition by gender interaction was not statistically significant $(F(3,57)=0.94, p$ $=.015)$. Because of limited numbers, race was not included in further analyses.

\section{DESIGN AND CONDITIONS}

A pre- and postexperimental and nonspecific treatment group design was used to assess the effects of an intensive prereading intervention on the literacy skills and social behavior of kindergarten children at risk for BD and reading difficulties. Children assigned to the experimental condition received one-to-one tutoring (i.e., Stepping Stones to Literacy; Nelson, Cooper, \& Gonzalez, 2004) by trained tutors in pivotal prereading skills (e.g., letter knowledge and phonemic awareness) for 25 sessions. Children in both the experimental and nonspecific treatment condition continued to receive the literacy instruction provided by their teachers.

\section{CORE KINDERGARTEN LITERACY INSTRUCTION}

Teachers in the participating schools did not use a formal basal series to guide their literacy instruction. Teachers addressed two primary literacy 


\begin{tabular}{|c|c|c|c|c|c|c|c|c|}
\hline \multirow[b]{3}{*}{ Demographic Variable } & \multicolumn{8}{|c|}{ Condition } \\
\hline & \multicolumn{4}{|c|}{ Experimental } & \multicolumn{4}{|c|}{ Nonspecific Treatment } \\
\hline & $\mathrm{N}$ & $\%$ & M & SD & $\mathrm{N}$ & $\%$ & M & SD \\
\hline \multicolumn{9}{|l|}{ Gender } \\
\hline Male & 35 & 74 & & & 12 & 75 & & \\
\hline Female & 12 & 26 & & & 4 & 25 & & \\
\hline \multicolumn{9}{|l|}{ Race } \\
\hline African American & 6 & 13 & & & 3 & 19 & & \\
\hline Asian American & 1 & 1 & & & 0 & 0 & & \\
\hline Caucasian & 35 & 75 & & & 12 & 75 & & \\
\hline Hispanic & 5 & 11 & & & 1 & 6 & & \\
\hline \multicolumn{9}{|l|}{ Lunch Status } \\
\hline Regular & 25 & 53 & & & 10 & 62 & & \\
\hline Free or Reduced & 22 & 47 & & & 6 & 38 & & \\
\hline Age & & & 5.1 & .33 & & & 5.2 & .38 \\
\hline \multicolumn{9}{|l|}{ ESP Scores } \\
\hline Critical Events Index & & & 55.8 & 6.9 & & & 52.4 & 5.6 \\
\hline Maladaptive Behavior & & & 66.2 & 8.3 & & & 70.5 & 6.1 \\
\hline Adaptive Behavior & & & 65.8 & 8.3 & & & 67.9 & 6.1 \\
\hline
\end{tabular}

areas sequentially across the kindergarten year. The first focused on prereading skills, and instructional activities centered on concepts of print (e.g., parts of books and their function, predictions based on illustrations or portions of stories, connection of events in text and life, letter names). The second area focused on preparing the children to word read. Instructional activities centered on phonemic awareness, letter-sound correspondence, simple sight words, reading familiar text, writing letters, and conventionally spelled words. Teachers had access to the phonics supplement of the Open Court reading program (Adams et al., 2002), and could use it as a part of their early literacy development activities. No formal core basal reading series was used by any of the teachers. No direct observations were conducted to describe or contrast the literacy instructional activities used by teachers.

\section{EXPERIMENTAL CONDITION}

The study implemented the Stepping Stones to Literacy program, in addition to the core kindergarten literacy instruction, for children in the experimental condition. The addition of the prereading intervention to the core kindergarten literacy instruction (rather than substitution for all or a part) was purposeful. Stepping Stones is a 
cohesive and intensive preventative prereading intervention for young children who are at risk of reading difficulties (Nelson, Cooper, \& Gonzalez, 2004) and is designed to supplement the core literacy instruction being offered. All Stepping Stones lessons are scripted (i.e., include all instructional prompts and activities). Thus, all of the children received the core literacy instruction and supplementary prereading intervention.

The lessons were delivered in a one-to-one format by trained paraprofessional-level tutors (project staff) during the school day at a time that the teacher determined was least disruptive to the child's educational program. The tutor training included several stages: presentation of the theory of and rationale for Stepping Stones; description and modeling of instructional activities; tutor practice of instructional activities with each other, with opportunity for corrective feedback; and tutor presentation of three complete, randomly selected lessons. The tutors were required to implement at least $90 \%$ of the Stepping Stones lesson components (i.e., $n=15$ ) as prescribed prior to tutoring children. Finally, following training, tutors were observed and provided corrective feedback, if necessary, while tutoring children during the first five lessons.

The Stepping Stones Lesson Book contains 25 lessons and a section on serial processing or rapid automatic naming (10 activities that provide children practice processing known sets of colors, numbers, and objects in a left-to-right format). During each daily lesson of 10 to $20 \mathrm{~min}$ utes, children were guided through a set of instructional activities designed to promote six pivotal prereading skills: identification, manipulation, and memory of environmental sounds (parallel phonemic awareness tasks); letter names; sentence meanings; phonological awareness; phonemic awareness; and serial processing or rapid automatic naming.

Identification, Manipulation, and Memory of Environmental Sounds. Five instructional activities were used to teach children a set of pivotal sound identification, manipulation, and memory skills necessary for them to fully benefit from instructional activities.

- Sounds in isolation (Lessons 1-5). Children were instructed to listen for the name of an an- imal articulated by the instructor within the context of a nursery rhyme.

- Sound relationships (Lessons 1-5). Children were instructed to identify the sound associated with a picture of an animal, and to identify the picture of the animal associated with a sound of an animal.

- Sounds in sequence (Lessons 6-10). Children were instructed to identify the sequence of sounds articulated by the instructor.

- Sound expectations (Lessons 6-10). Children were instructed to identify unexpected words articulated by the instructor within the context of a nursery rhyme.

- Omit a sound (Lessons 11-14). Children were instructed to identify an environmental sound (e.g., dog barking, cough) omitted from a sequence of sounds articulated by the instructor.

Letter Naming and Sentence Meaning. Five instructional activities were used to teach children pivotal conventional early literacy skills:

- Sentence recognition (Lessons 1-6). Children were instructed to identify what was happening in each sentence of a nursery rhyme articulated by the instructor.

- Sentence generation (Lessons 6-10). Children were instructed to generate descriptions of what might be happening in a picture.

- Letter names (Lessons 1-25). Children were instructed to point and say letter names presented in a left-to-right format.

- Letter name practice (Lessons 5-25). Children were instructed to point and say as many letter names presented in a left-to-right format as they could in 1 minute.

- Letter name cumulative review (Lessons 11, 15, 19-20, 23-25). Children were instructed to point and say as many letter names presented in a left-to-right format as they could in 1 minute.

The latter two instructional activities provided immediate and intermittent review of letter names and serial processing practices.

Phonological Awareness. Five instructional activities were used to teach children to be consciously aware of the linguistic structure of the largest units of oral language (e.g., words, syllables): 
- Rhyme identification (Lessons 1-7). Children were instructed to identify words that rhyme with one another in the context of a nursery rhyme.

- Rhyme generation (Lessons 8-14). Children were instructed to generate several words that rhyme with a word articulated by the instructor.

- Word segmentation (Lessons 11-14). Children were instructed to clap every time they heard a word in a nursery rhyme articulated by the instructor.

- Syllable blending (Lessons 11-14). Children were instructed to generate the word associated with two or more blended syllables articulated by the instructor.

- Onset-rime blending (Lessons 15-17). Children were instructed to generate the word associated with the initial sound and the rest of the word articulated by the instructor.

Phonemic Awareness. Four instructional activities were used to teach children to be consciously aware of the smallest units of oral language (i.e., phonemes):

- Phoneme deletion (Lessons 15-18). Children were instructed to generate the remaining word after the initial phoneme has been deleted from a word articulated by the instructor.

- Phoneme identification (Lessons 18-21). Children were instructed to identify each phoneme within a word articulated by the instructor.

- Phoneme segmentation (Lessons 15-25). Children were instructed to generate the initial, medial, and final phonemes within a word articulated by the instructor.

- Phoneme change (Lessons 19-25). Children were instructed to generate a new word by changing the initial, final, or medial phoneme within a word articulated by the instructor.

Serial Processing. One instructional activity was used to enhance children's serial processing skills: Children were presented with an array of visually depicted known stimuli representing linguistic information (e.g., series of five colors, letters, numbers, known objects) placed in random order.

\section{NONSPECIFIC TREATMENT CONDITION}

Children in the nonspecific treatment condition received the core kindergarten literacy instruction offered in the classroom. No attempt (e.g., staff development activities directed at language development, prereading, or word reading) was made to change any of the early literacy instructional activities provided to children by teachers.

\section{TREATMENT FIDELITY}

A tutor self-evaluation measure and direct observations were used to assess treatment fidelity throughout the duration of the study. The selfevaluation measure consisted of 17 items associated with three stages of the implementation of the Stepping Stones program: before tutoring begins (e.g., I had all needed materials ready and available for use); during the tutoring session (e.g., I followed the appropriate sequence of activities for the lesson; I required the student to follow specific instructions for each activity); and after the tutoring session (e.g., I coached the student back into the instructional activity in his or her classroom). Tutors rated each item on a 4point Likert-type scale that ranged from never to always. Two trained independent observers conducted random direct observations of each tutor seven times, monitoring the tutor's implementation of the program components. Observers and tutors were trained simultaneously. The observers studied the definitions for each of the components on the treatment fidelity observation form, then observed the tutor practice sessions. During these sessions, observer scores were compared and discrepancies discussed. Observers were required to obtain at least $90 \%$ agreement across instructional components before beginning treatment fidelity observations.

\section{DEPENDENT MEASURES}

Individually administered standardized measures were used to assess four literacy and three social behavior areas (i.e., phonological awareness, word reading, letter naming speed, and rapid automatic naming; and classroom competence, emotional and behavioral self-control, self confidence, respectively).

Phonological Awareness. The current study used the Comprehensive Test of Phonological 
Processing (CTOPP) Phonological Awareness (PA) composite. The PA composite is a norm-referenced assessment that provides an overall measure of a child's phonological awareness skills (Wagner, Torgesen, \& Rashotte, 1999), and comprises the Elision, Blending Words, and Sound Matching subtests. The Elision subtest includes 20 items that measure the extent to which the child can say a word and then say what is left after dropping out designated sounds. The Blending Words subtest includes 20 items that measure the extent to which the child can combine sounds to form words. The Sound Matching subtest includes 20 items. The coefficient alpha for the PA composite ranges from .95 to .98 across ethnic groups and the overall test-retest reliability was .77 (Wagner et al., 1999).

Word Reading. The Woodcock Reading Mastery Tests-Revised (WRMT-R) Basic Skills cluster (Woodcock, 1998), a norm-referenced measure of reading ability, comprises the Word Identification (WI) and Word Attack (WA) subtests. The WI and WA subtests of the WRMT-R were used to measure children's word reading skills. The WI subtest includes 51 items arranged in order of difficulty that measure the child's ability to read letters/words presented in uppercase and lowercase. The WA subtest includes 106 items arranged in order of difficulty that measure the child's ability to decode nonsense words. The WRMT-R Basic Skills cluster has a mean score of 100 and a standard deviation of 15 . The split-half reliability is 0.97 and 0.87 for the WRMT-R WI and WA subtests, respectively.

Letter Naming Speed. The DIBELS Letter Naming Fluency (LNF) probe measures the speed with which a child can name letters (Good \& Kaminski, 2002). The child is presented with a page of random uppercase and lowercase letters and asked to name as many letters as he or she can in 1 minute. The score is the total number of letters named correctly in 1 minute. The LNF has an alternative reliability of .93 (Hintze, Ryan, \& Stoner, 2002).

Rapid Automatic Naming. The CTOPP Rapid Naming (RN) composite is a norm-referenced assessment that provides an overall measure of the child's ability to efficiently retrieve phonological information from long-term memory. The RN composite comprises the Rapid Color Nam- ing and Rapid Object Naming subtests. The Rapid Color Naming subtest includes 72 items that measure the speed with which a child can name the colors of a series of different colored blocks printed on two pages. The Rapid Object Naming subtest includes 72 items that measure the speed with which a child can name a series of objects on two pages. The CTOPP RN composite has a mean score of 100 and a standard deviation of 15 . The coefficient alpha for the RN composite ranges from .83 to .91 across ethnic groups and the overall and test-retest reliability was .90 (Wagner et al., 1999).

Social Behavior. The Behavioral and Emotional Rating Scale (BERS) is designed to identify a student's behavioral and emotional strengths (Epstein \& Sharma, 1998). The BERS School Functioning (9 items), Interpersonal Strength (15 items), and Intrapersonal Strength (11 items) subscales were used in the current study to assess children's competence in the classroom, emotional and behavioral self-control, and self-confidence, respectively. The subscales contain items written in a positive, strength-based format (e.g., pays attention). Each item is judged on a 4-point scale $(0=$ not at all like, $1=$ not much like, $2=$ like 3 = very much like). Each of the BERS subscales has a mean score of 10 and a standard deviation of 3. The test-retest and internal consistency for the BERS subscales range from .71 to .94 (Epstein \& Sharma).

\section{RESULT S}

\section{TREATMENT FIDELITY}

The tutor-reported overall mean percentage of Stepping Stones intervention program components implemented correctly (i.e., items rated as always implemented) was $96 \%(S D=2.87)$. Independent observations were conducted randomly on a total of 62 tutoring sessions. The percentage of intervention program components implemented correctly was $98 \%(S D=.72)$. Interobserver agreement was conducted on $35 \%$ of the sessions. Interobserver agreement was $100 \%$. 
PREINTERVENTION LITERACY AND SOCIAL BEHAVIOR LEVELS

Descriptive statistics were computed initially on the preintervention literacy skills and social behaviors of children in the experimental and nonspecific treatment groups who failed to complete the study, to assess if they differed substantially from one another or from those who remained in the study. All of the children who did not complete the study failed to get any items correct on the WRMT-R WI and WA measures. The mean scores and associated standard deviations of children in the experimental and nonspecific treatment groups on the remaining literacy and social behavior measures were, respectively, (1) CTOPP PA $(x=85.5, S D=5.7$ vs. $x=87.5, S D=6.9)$, (2) CTOPP RN $(x=83.1, S D=12.8$ vs. $x=$ 86.7, $S D=12.9)$, (3) DIBELS LNF $(x=12.5, S D$ $=11.4$ vs. $x=13.1, S D=8.4$ ), (4) BERS School Functioning $(x=7.1, S D=2.6$ vs. $x=7.2, S D=$ 2.3), (5) BERS Interpersonal ( $x=7.7, S D=1.9$ vs. $x=7.2, S D=2.2$ ), and (6) BERS Intrapersonal ( $x=8.6, S D=2.5$ vs. $x=8.8, S D=3.2$ ). Close inspection of the means and associated standard deviations revealed that children in the experimental and nonspecific treatment conditions did not appear to differ substantially from one another. The preintervention means and standard deviations for children in the experimental and nonspecific treatment conditions who completed the study are presented in Table 2. Similarly, the means scores of children who failed to complete do not appear to differ substantially from those who did.

The value of missing data cannot be verified or tested (Allison, 2002); however, these results suggest that the missing data do not appear to be a function of initial literacy skills and/or social behavior as well as experimental condition.

The results of a one-way MANOVA applied to the mean preintervention WRMT-R, WI and WA, CTOPP PA, DIBELS LNF, and CTOPP RN scores $(F(5,57)=1.49, p>.05)$ revealed no statistically significant preintervention differences in the phonological awareness, word reading, letter naming speed, and rapid automatic naming skills of children in the experimental and nonspecific treatment conditions. Similarly, the results of a one-way MANOVA applied to the mean preintervention BERS School Functioning, Interpersonal Strength, and Intrapersonal Strength subscale scores $(F(3,59)=2.09, p>.05)$ revealed no statistically significant preintervention differences in the classroom competence, emotional and behavioral self-control, and self-confidence of children in the experimental and nonspecific treatment conditions. Taken together, these results demonstrate the comparability of the treatment conditions in terms of preintervention literacy skills and social behavior of children.

\section{CHANGES IN LITERACY SKILLS}

The mean preintervention, postintervention, and change scores for the experimental and nonspecific treatment conditions and associated $F$ values and effect sizes are presented in Table 2. Children in the experimental group generally showed substantial improvements in their phonological awareness, word reading, and rapid automatic naming skills; children in the nonspecific treatment group showed no or small improvements in these skills. Mean changes in the experimental and nonspecific treatment groups' phonological awareness, word reading, letter naming speed, and rapid automatic naming measures were analyzed in Condition (Experimental, Nonspecific Treatment) X Gender (Female, Male) X Change (Preintervention, Postintervention) Analysis of Variance (ANOVAs), with the latter variable being a within-subject factor. Furthermore, Bonferonni corrections were used to set the significance level $(.05 / 5=.01)$. With one exception (CTOPP RN), significant Group X Change interaction effects were obtained. These results demonstrated that children in the experimental group made statistically significant improvements in their phonological awareness (i.e., CTOPP PA: $F(1,61)=7.11, p=.006$ ), word reading (i.e., WRMT-R WI: $F(1,61)=13.94, p=.000$; WRMT-R WA: $F(1,61)=11.46, p=.001)$, and letter naming speed $(F(1,61)=16.50, p=.001)$ skills relative to children in the nonspecific treatment group. Children in the experimental and nonspecific treatment groups did not show statistically significant differential changes in their CTOPP RN scores $(F(1,61)=1.56, p=.213)$. Additionally, the gender by change interaction effect was not statistically significant in all cases. 


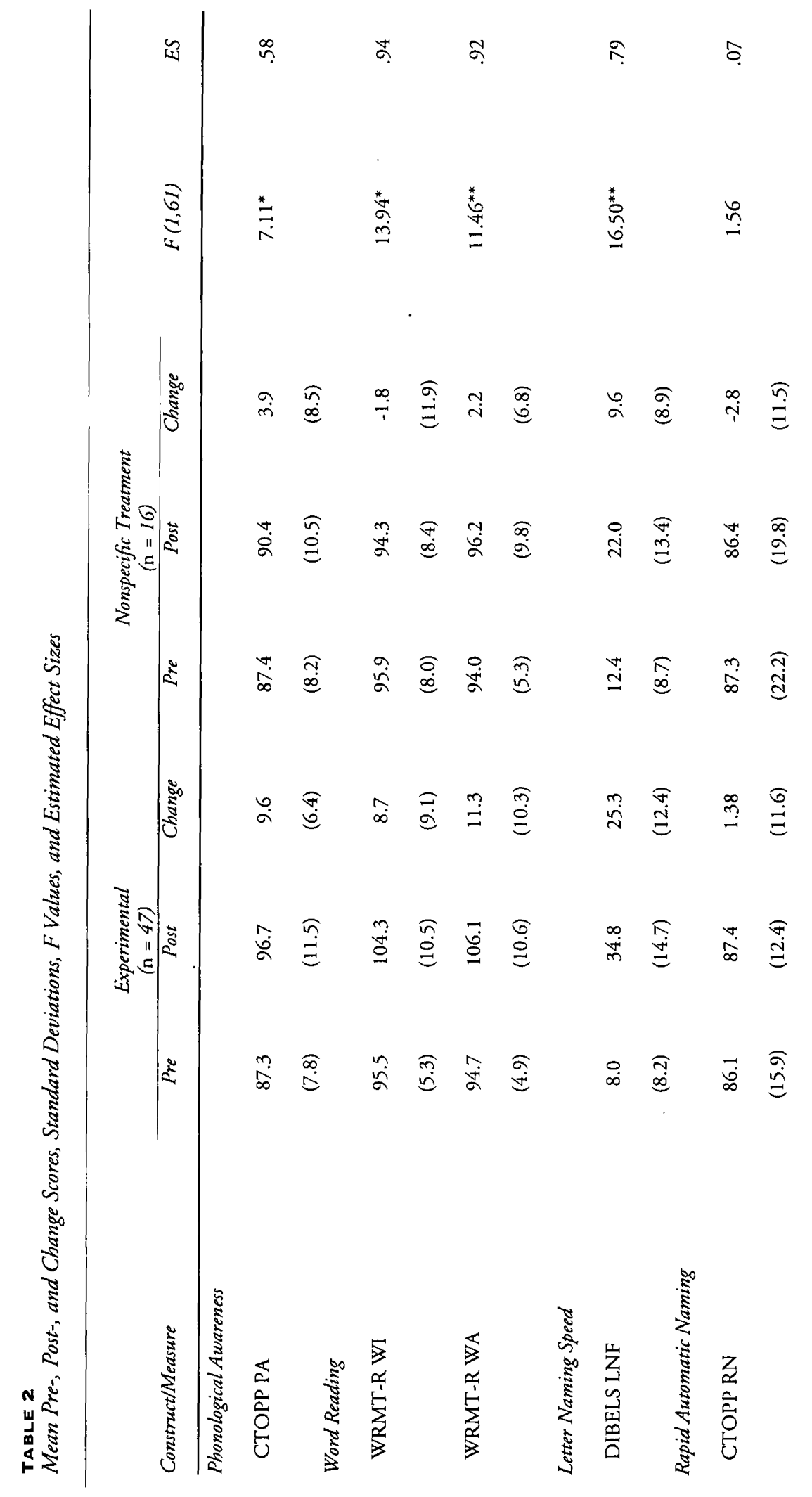




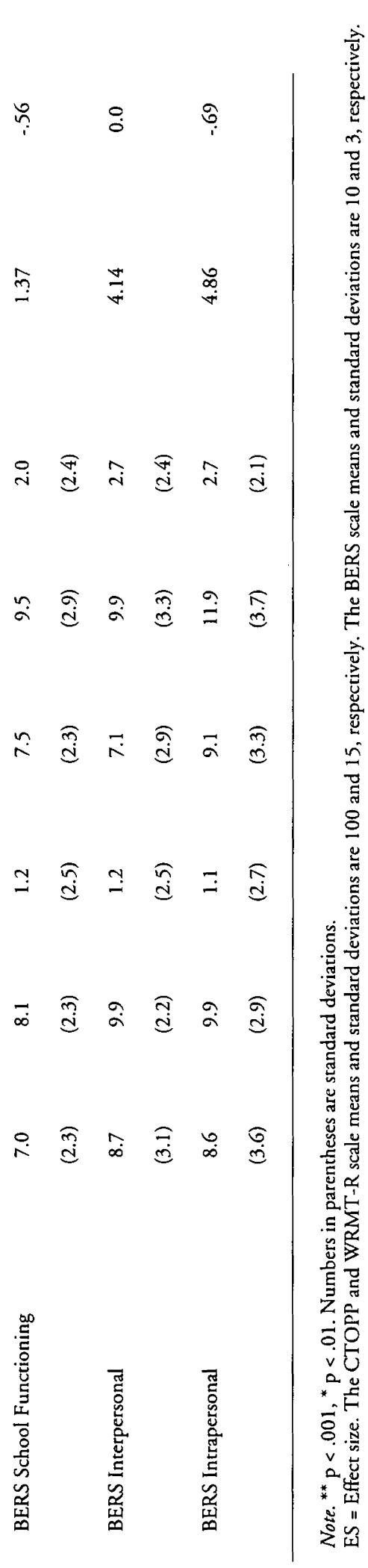

The effect sizes for the phonological awareness, word reading, letter naming speed, and rapid automatic naming measures are presented in Table 2. Effect sizes were calculated by dividing the difference between the experimental and nonspecific treatment group mean posttest scores by the pooled standard deviation (Cooper $\&$ Hedges, 1994). The obtained estimates were then corrected for bias due to sample size using a factor provided by Hedges and Olkin (1985). The 95\% confidence bands for the effect sizes were computed using percentiles from the standard normal distribution and the asymptotic variance of the standardized mean difference (Hedges \& Olkin). Effect size estimates for the phonological awareness, word reading, and rapid automatic naming measures were, respectively, (1) CTOPP PA $=.55$ (confidence interval $=-.02$ to 1.13 ), (2) WRMT$\mathrm{R} \mathrm{WI}=.99$ (confidence interval $=.39$ to 1.58 ), WRMT-R WA $=.92$ (confidence interval $=.33$ to 1.51), and (3) CTOPP RN $=.07$ (confidence interval $=-.50$ to .64$)$, and DIBELS LNF $=.79$ (confidence interval $=.17$ to 1.42 ).

\section{CHANGES IN SOCIAL BEHAVIOR}

The mean preintervention, postintervention, and mean change scores for the experimental and nonspecific treatment conditions and associated $F$ values are presented in Table 2. Children in the experimental and nonspecific treatment groups showed relatively small improvements in classroom competence, emotional and behavioral selfcontrol, and self-confidence. Furthermore, children in the nonspecific treatment group showed greater gains than those in the experimental group in all cases. Mean changes in the experimental and nonspecific treatment groups' classroom competence, emotional and behavioral self-control, and self-confidence measures were analyzed in Condition (Experimental, Nonspecific Treatment) X Gender (Female, Male) X Change (Preintervention, Postintervention) ANOVAs, with the latter variable being a withinsubject factor. Bonferonni corrections were used to set the significance level $(.05 / 3=.016)$. No statistically significant Group X Change interaction effects were obtained in the case of the BERS School Functioning Interpersonal Strengths, Intrapersonal Strengths subscales. These results demonstrated that children in the experimental 
TABLE 3

Mean Change Scores and Standard Deviations for Children Sharing the Same Classroom

\begin{tabular}{|c|c|c|}
\hline Construct/Measure & $\begin{array}{c}\text { Experimental } \\
(\mathrm{n}=9)\end{array}$ & $\begin{array}{c}\text { Nonspecific Treatment } \\
(\mathrm{n}=16)\end{array}$ \\
\hline \multicolumn{3}{|l|}{ Phonological Awareness } \\
\hline \multicolumn{2}{|l|}{ CTOPP PA } & $(8.5)$ \\
\hline \multicolumn{3}{|l|}{ Word Reading } \\
\hline \multirow[t]{2}{*}{ WRMT-R WI } & 7.6 & -1.8 \\
\hline & (7.5) & (11.9) \\
\hline \multirow[t]{2}{*}{ WRMT-R WA } & 11.3 & 2.2 \\
\hline & $(10.9)$ & $(6.8)$ \\
\hline \multicolumn{3}{|l|}{ Letter Naming Speed } \\
\hline \multirow[t]{2}{*}{ DIBELS LNF } & 21.4 & 9.6 \\
\hline & $(9.2)$ & $(8.9)$ \\
\hline \multicolumn{3}{|l|}{ Rapid Automatic Naming } \\
\hline \multirow[t]{2}{*}{ CTOPP RN } & 1.7 & -2.8 \\
\hline & (9.3) & $(11.46)$ \\
\hline \multicolumn{3}{|l|}{ Social Behavior } \\
\hline \multirow[t]{2}{*}{ BERS School Functioning } & 0.5 & 2.0 \\
\hline & $(1.8)$ & $(2.4)$ \\
\hline \multirow[t]{2}{*}{ BERS Interpersonal } & 1.1 & 2.7 \\
\hline & (1.1) & (2.4) \\
\hline \multirow[t]{2}{*}{ BERS Intrapersonal } & 0.9 & 2.7 \\
\hline & $(1.1)$ & $(2.1)$ \\
\hline
\end{tabular}

and nonpecific treatment groups showed similar improvements in classroom competence (i.e., BERS School Functioning: $F(1,61)=1.37, p=$ .266), emotional and behavioral self-control (i.e., BERS Interpersonal Strengths: $F(1,61)=4.14, p$ $=.045$ ), and self-confidence (i.e., BERS Intrapersonal Strengths: $F(1,61)=4.86, p=.077)$. The gender by change interaction effect was not statistically significant in all cases.

The effect sizes for the classroom competence, emotional and behavioral self-control, and self-confidence measures are presented in Table 2. The same procedures used to calculate the effect sizes for the literacy measures were used. Effect size estimates for the classroom competence, emotional and behavioral self-control, and self-confidence measures were, respectively, (1) BERS School Functioning $=-.56$ (confidence interval $=$ -1.14 to .01$)$, (2) BERS Interpersonal Strengths = 0.0 (confidence interval $=-.57$ to .57 ), and (3) BERS Intrapersonal Strengths $=-.69$ (confidence interval $=-1.27$ to -.11 ). These findings indicated that children in the nonspecific treatment condition made negligible to moderate gains in their social behavior relative to their counterparts in the experimental condition. 
POTENTIAL INFLUENCE OF CORE KINDERGARTEN LITERACY INSTRUCTION ON

TREATMENT EFFECTS

The mean literacy and social behavior change scores for children in the experimental $(n=9)$ and nonspecific treatment $(n=16)$ conditions who shared the same classrooms are presented in Table 3. The mean literacy change scores of children in the experimental condition were consistently greater than those of children in the nonspecific treatment condition. In contrast, the mean social behavior change score of children in the nonspecific treatment condition were consistently greater than those of children in the experimental condition. The pattern of change in the literacy skills and social behavior of children in the experimental and nonspecific treatment conditions were consistent with those for the entire sample (see Tables 2 and 3). These findings (albeit tentative) suggest that the core kindergarten literacy instruction did not have a differential influence on the treatment effects.

\section{DISCUSSION}

This study investigated the effects of a cohesive and intensive prereading intervention program on the beginning reading skills and social behavior of kindergarten children at risk for $\mathrm{BD}$ and reading difficulties. Children who received the prereading intervention showed statistically significant gains in their phonological awareness, word reading, and letter naming speed skills relative to their counterparts in the nonspecific treatment condition. The magnitude of the improvements in children's phonological awareness, word reading, and letter naming speed skills (i.e., effect sizes) were educationally significant (range $=0.58$ to .94 ). Effect sizes in the range of 0 to .3 are considered small, 0.3 to 0.8 are considered moderate, and 0.8 and above are considered large (Cohen, 1988). In contrast, children who received the prereading intervention did not show statistically or educationally significant gains in their rapid automatic naming skills compared to their counterparts in the nonspecific treatment condition.

Comparing the mean change scores of children in the experimental condition sharing a classroom with children in the nonspecific treat- ment condition provided converging evidence that the prereading intervention had a positive effect on the phonological awareness, word reading, and rapid letter naming skills of children at risk for $\mathrm{BD}$ and reading difficulties. Although we were unable to fully assess the potential contribution of the core-kindergarten literacy instruction on the treatment effects, the overall pattern of gains in literacy skills paralleled those of the entire sample.

These generally positive literacy effects are consistent with previous research that documented improvements in the early literacy skills of kindergarten children at risk for $\mathrm{BD}$ and reading problems using intensive cohesive core and supplementary programs (Trout, Epstein, Mickelson, Nelson, \& Lewis, 2003) as well as intervention programs (Nelson, 2005). The moder-

\section{Children in the experimental group gen- erally showed substantial improvements in their phonological awareness, word reading, and rapid automatic naming skills.}

ate-to-large effect sizes obtained in this study are generally consistent with those reported by $\mathrm{Nel}-$ son et al. (2005) in an earlier efficacy study of the prereading intervention used in this investigation. The outcomes of the present study may not be surprising, as one would expect children who receive intensive one-to-one instruction beyond the literacy instruction provided in the classroom to show improvements in their literacy skills. Such improvements provide support to multi-tiered instructional models (e.g., Vaughn, Linan-Thompson, \& Hickman, 2003). However, the outcomes of the present study are noteworthy given that the selection criteria identified a group of children at risk for $\mathrm{BD}$ and reading difficulties. Children with $\mathrm{BD}$ generally have not responded positively to ordinarily effective literacy interventions (Al Otaiba \& Fuchs, 2002; Nelson et al., 2003; Torgesen et al., 1999). Further, researchers have reported that children with letter naming speed deficits are likely to experience limited growth in their literacy skills (Stage, Sheppard, Davidson, \& Browning, 2001). This lack of growth was gener- 


\section{The mixed results of this study. . . illus- trate the complex relationship between $B D$ and academic deficits.}

ally evident for children in the nonspecific treatment condition.

In contrast to the literacy outcomes, children who received the prereading intervention failed to show improvements in their social behavior relative to their counterparts in the nonspecific treatment condition. There were greater changes in teacher ratings of the classroom competence, emotional and behavioral self-control, and self-confidence of children in nonspecific treatment condition relative to their counterparts in the experimental condition. The obtained small-to-moderate negative effect sizes (range 0.0 to -69 ) in social behavior support the conclusion that children receiving the prereading intervention failed to show improvements in their social behavior beyond their counterparts in the nonspecific treatment condition. Generally, these findings are consistent with some previous research on the collateral effects of literacy interventions on the social behavior of children with and at risk for BD (e.g., Lane, 1999). These findings, however, are in contrast with previous research that found a positive effect of literacy interventions on the social behavior of children at risk for $\mathrm{BD}$ and reading difficulties (e.g., Lane et al., 2002).

The mixed results of this study and others designed to investigate the collateral effects of literacy interventions on the social behavior of children with and at risk for BD (e.g., Lane, 1999) illustrate the complex relationship between $\mathrm{BD}$ and academic deficits. Much of the research on the origins, prevalence, and consequences of $\mathrm{BD}$ among school-age children (e.g., Hinshaw, 1992; Loeber \& Farrington, 1998; Maguin \& Loeber, 1996; Nelson, Benner, Lane, \& Smith, 2004; Tonry \& Moore, 1998) suggests that BD is at least partially an outcome of academic achievement deficits and no doubt it is for some children. It is equally likely that for many children, academic achievement deficits are an outcome of their $\mathrm{BD}$. If children begin schooling with $\mathrm{BD}$ ac- quired prior to school, such behaviors will affect their ability to attend to academic instruction in all areas. Further, for some children, academic achievement deficits and BD may exist in a reciprocal relationship.

\section{LIMITATIONS AND FUTURE RESEARCH}

As with all studies, this investigation had limitations that should be addressed by future research. First, it is certainly plausible that teacher effects may have influenced the study outcomes. No information (i.e., treatment fidelity) was collected on the literacy instruction practices provided to children in the nonspecific treatment condition. The pattern of change in literacy skills and social behavior of children in the experimental and nonspecific treatment conditions sharing the same classroom appears to be consistent with those for the entire sample. Future research should document the instructional practices used by teachers to clarify the "value-added" effects of the prereading intervention.

Second, the sample of children was drawn from schools in one geographic location with a limited participant sample and may not be representative of the general population of kindergarten children at risk for BD and reading difficulties. It is possible that the findings may not generalize to other students in other geographical regions and diverse populations. Future research should replicate these findings across varied contexts and diverse populations including young children with identified emotional disturbance and BD who are at risk for reading difficulties.

Third, the modest sample size prohibited the random assignment of an equal number of children to the experimental and nonspecific treatment conditions, and limited the use of more sophisticated analyses to explore possible interaction effects between variables. Because of low cell sizes, it was not possible to conduct factorial multivariate analyses of variance to investigate interactions among such variables as, for example, type of reading difficulty (phonological, serial rapid automatic naming, phonological and serial rapid automatic naming) and race. Such analysis might determine the effect of type of reading difficulty on literacy and social behavior outcomes and 
whether the outcomes differ between ethnic groups.

Fourth, only one type of behavior rating scale was used. In this study, social behavior was assessed via a standardized rating scale (BERS). It may be that children receiving the prereading intervention would have demonstrated improvements in social behavior if measures were more closely linked to social interactions during literacy instruction (e.g., direct observations of on-task behaviors during reading instruction).

Fifth, the extent to which literacy outcomes were affected by including rapid automatic naming practice is unclear. Although rapid automatic naming deficits are predictive of reading failure

\section{Cohesive and intensive core, supplemen- tary, and intervention programs delivered in a one-to-one instructional format in addition to core kindergarten literacy in- struction appear to produce positive and reliable treatment effects.}

(e.g., Compton, 2003; Stage et al., 2001), the extent to which instruction in rapid automatic naming skills may extend the benefits of our current early literacy interventions remains unclear. Previous intervention research that focused solely on enhancing children's rapid automatic naming skills suggests that such skills are difficult to improve (De Jong \& Vrielink, 2004).

Sixth, the intervention's social validity was not assessed. Although a majority of the schools continued to use the prereading intervention following the study period, the intervention was targeted more generally at children at risk for reading difficulties. Future research should use formal measures of the social validity of the prereading intervention.

Finally, this study is part of a relatively small body of reading research conducted with children with or at risk for BD and reading difficulties. A comprehensive program of research should be undertaken to identify the types of core, supplementary, and intervention programs that work with children with or at risk for BD and to illuminate the learner and contextual characteristics that influence treatment effects. Unfortunately, to date there is relatively little research with which to guide education decision makers regarding effective literacy practices for children with BD.

\section{IMPLICATIONS}

Bearing in mind these limitations, two implications are evident. First, cohesive and intensive core, supplementary, and intervention programs delivered in a one-to-one instructional format in addition to core kindergarten literacy instruction appear to produce positive and reliable treatment effects (Nelson et al., 2005; Trout et al., 2003). The elements of cohesive and intensive interventions include (a) a scientifically based scope and sequence that ensures skill acquisition and consolidation, (b) instructional prompts to guide the teacher, (c) instructional activities to guide the learner, (d) effective error correction procedures, and (e) progress monitoring strategies. Second, it appears that cohesive and intensive core, supplementary, and intervention programs should be delivered at school entry. Previous research conducted with first-grade children at risk for BD and reading problems has been mixed (Epstein, Nelson, Trout, \& Mooney, in press). Additionally, educators seeking to improve the outcomes of children at risk for BD and reading difficulties should attempt to apply both behavior and literacy interventions. The results of this study suggest that, in general, relying on literacy interventions to improve the social behavior of children at risk for $\mathrm{BD}$ may have limited effects at best.

\section{RE FERENCES}

Adams, M. J., Bereiter, C., Carruthers, I., Case, R., Hirshberg, J., McKeough, A., et al. (2002). Open court reading. Columbus, $\mathrm{OH}$ : SRA/McGraw Hill.

Allison, P. D. (2002). Missing data. Thousand Oaks, CA: Sage.

Al Otaiba, S., \& Fuchs, D. (2002). Characteristics of children who are unresponsive to early literacy instruction. Remedial and Special Education, 23, 300-316.

Anderson, J. A., Kutash, K., \& Duchnowski, A. J. (2001). A comparison of the academic progress of students with EBD and students with LD. Journal of Emotional and Behavioral Disorders, 9, 106-115. 
Berninger, V. W., Abbott, R. D., Billingsley, F., \& Nagy, W. (2001). Processes underlying timing and fluency of reading: Efficiency, automaticy, coordination, and morphological awareness. In M. Wolf (Ed.), Dyslexia, fluency, and the brain (pp. 383-414). Timonium, MD: York Press.

Cohen, J. (1988). Statistical power analysis for the behavioral sciences. New York: Academic Press.

Compton, D. L. (2003). Modeling the relationship between growth in rapid naming speed and growth in decoding skill in first grade children. Journal of Educational Psychology, 95, 225-240.

Cooper, H., \& Hedges, L. V. (1994). The handbook of research synthesis. New York: Russell Sage Foundation.

Cutting, L. E., \& Denckla, M. B. (2001). The relationship of serial rapid naming and word reading in normally developing readers: An exploratory model. Reading and Writing: An Interdisciplinary Journal, 14, 673-705.

De Jong, P. F., \& Vrielink, L. O. (2004). Rapid automatic naming: Easy to measure, hard to improve (quickly). Annals of Dyslexia, 54, 65-88.

Elliott, S., \& Gresham, F. (1991). Social skills intervention guide: Practical strategies for social skills training. Circle Pines, MN: American Guidance Service.

Epstein, M. H., \& Cullinan, D. (1983). Academic performance of behaviorally disordered and learning-disabled pupils. Journal of Special Education, 17, 303-307.

Epstein, M. H., Nelson, J. R., Trout, A. L., \& Mooney, P. (in press). Achievement and emotional disturbance: Academic status and intervention research. In M. H. Epstein, K. Kutash, \& A. J. Duchnowski (Eds.), Outcomes for children and youth with emotional and behavioral disorders and their families: Programs and evaluation best practices (2nd ed.). Austin, TX: PROED.

Epstein, M. H., \& Sharma, J. M. (1998). Behavioral and emotional rating scale: $A$ strength-based approach to assessment. Austin, TX: PRO-ED

Falk, K. B., \& Wehby, J. H. (2001). The effects of peer-assisted learning strategies on the beginning reading skills of young children with emotional or behavioral disorders. Behavioral Disorders, 26, 344-359.

Gajar, A. (1979). Educable mentally retarded, learning disabled, emotionally disturbed: Similarities and differences. Exceptional Children, 45, 470-472.

Good, R. H., \& Kaminski, R. A. (Eds.) (2002). Dynamic indicators of basic early literacy skills (6th ed.). Eugene, OR: Institute for the Development of Educational Achievement. Available: http://dibels.uoregon.edu
Greenbaum, P. E., Dedrick, R. F., Friedman, R. M., Kutash, K., Brown, E. C., Lardieri, S. P., \& Pugh, A. M. (1996). National Adolescent and Child Treatment Study (NACTS): Outcomes for children with serious emotional and behavioral disturbance. Journal of Emotional and Behavioral Disorders, 3, 130-146.

Hedges, L. V., \& Olkin, I. (1985). Statistical methods for meta-analysis. San Diego, CA: Academic Press.

Hinshaw, S.P. (1992). Externalizing behavior problems and academic underachievement in childhood and adolescence: Casual relationships and underlying mechanisms. Psychological Bulletin, 111, 127-155.

Hintze, J. M., Ryan, A. L., \& Stoner, G. (2002). Concurrent validity and diagnostic accuracy of the Dynamic Indicators of Basic Early Literacy Skills. Available http:// dibels.uorgeon.edu.

Jenkins, J. R., \& O'Connor, R. (2002). Early identification and intervention for young children with reading/learning disabilities. In R. Bradley, L. Danielson, \& D. P. Hallahan (Eds.), Identification of learning disabilities: Research to practice (pp. 99-151). Mahwah, $\mathrm{NJ}$ :Lawrence Erlbaum Associates.

Lane, K. L. (1999). Young students at risk for antisocial behavior: The utility of academic and social skills interventions. Journal of Emotional and Behavioral Disorders, 7, 211-224.

Lane, K. L., O'Shaughnessy, T. E., Lambros, K. M., Gresham, F. M., \& Beebe-Frankenberger, M. E. (2001). The efficacy of phonological awareness training with first-grade students who have behavior problems and reading difficulties. Journal of Emotional and Behavioral Disorders, 9, 219-231.

Lane, K. L., Wehby, J. H., Menzies, H. M., Gregg, R. M., Doukas, G. L., \& Munton, S. M. (2002). Early literacy instruction for first-grade students at risk for antisocial behavior. Education and Treatment of Children, 25, 438-458.

Loeber, R., \& Farrington, D. P. (Eds.). (1998). Serious \& violent juvenile offenders: Risk factors and successful interventions. Thousand Oaks, CA: Sage.

Maguin, E., \& Loeber, R. (1996). Academic performance and delinquency. In M. Tonry (Ed.), Crime and justice: A review of research (Vol. 20, pp. 145-264). Chicago: University of Chicago Press.

Mattison, R. E., Spitznagel, E. L., \& Felix, B. C. (1998). Enrollment predictors of the special education outcome for students with SED. Behavioral Disorders, 23, 243-256.

McEvoy, A., \& Welker, R. (2000). Antisocial behavior, academic failure, and school climate. Journal of Emotional and Behavioral Disorders, 8, 130-140. 
Meadows, N. B., Neel, R. S., Scott, C. M., \& Parker, G. (1994). Academic performance, social competence, and mainstream accommodations: A look at mainstreamed and non-mainstreamed students with serious behavioral disorders. Behavioral Disorders, 19, 170-180.

Nelson, J. R, Benner, G. J., \& Gonzalez, J. (2003). Learner characteristics that influence the treatment effectiveness of early literacy interventions: A meta analytic review. Learning Disabilities Research \& Practice, 18, 255-267.

Nelson, J. R., Benner, G. J., \& Gonzalez, J. (2005). An investigation of the effects of a prereading intervention on the early literacy skills of kindergarten children at risk of emotional disturbance and reading problems. Journal of Emotional and Behavioral Disorders, 13, 3-12.

Nelson, J. R., Benner, G. J., Lane, K., \& Smith, B. (2004). Academic skills of K-12 students with emotional and behavioral disorders. Exceptional Children, 71, 59-74.

Nelson, J. R., Cooper, C., \& Gonzalez, J. (2004). Stepping stones to literacy. Longmont, $\mathrm{CO}$ : Sopris West.

Scruggs, T. E., \& Mastropieri, M. A. (1986). Academic characteristics of behaviorally disordered and learning disabled students. Behavioral Disorders, 11, 184-190.

Shefelbine, J. (1998). Phonics chapters books 1-6: Teachers guide. New York: Scholastic.

Stage, S. A., Sheppard, J., Davidson, M., \& Browning, M. (2001). Prediction of first grader's growth in oral reading using their kindergarten letter-naming and lettersound fluency. Journel of School Psychology 39, 225-237.

Tonry, M., \& Moore, M. H. (Eds.) (1998). Youth violence. Chicago: University of Chicago Press.

Torgesen, J. K., \& Bryant, B. R. (1994). Phonological awareness training for reading. Austin, TX: PRO-ED.

Torgesen, J. K., Wagner, R. K., Rashotte, C. A., Lindamood, P., Rose, E., Conway, T., et al. (1999). Preventing reading failure in young children with phonological processing disabilities: Group and individual responses to instruction. Journal of Educational Psychology, 91, 579-593.

Trout, A. L., Epstein, M. H., Mickelson, W. T., Nelson, J. R., \& Lewis, L. M. (2003). Effects of a reading intervention for kindergarten students at risk of emotional disturbance and reading deficits. Behavioral Disorders, 28, 313-326.

Vaughn, S., Linan-Thompson, S., \& Hickman, P. (2003). Response to instruction as a means of identifying students with reading/learning disabilities. Exceptional Children, 69, 391-409.

Wagner, M. M. (1995). Outcomes for youths with serious emotional disturbance in secondary school and early adulthood. The Future of Children, 5, 90-111.

Wagner, R. K., Torgesen, J. K., \& Rashotte, C. A. (1999). Comprehensive Test of Phonological Processing (CTOPP). Longmont, CO: Sopris West.

Walker, H. M., Severson, H. H., \& Feil, E. G. (1995). Early screening project: $A$ woven child-find process. Longmont, CO: Sopris West.

Wilson, L., Cone, T., Bradley, C., \& Reese, J. (1986). The characteristics of learning disabled and other handicapped students referred for evaluation in the state of Iowa. Journal of Learning Disabilities, 19, 553-557.

Wolf, M., \& Bowers, P. G. (1999). The double-deficit hypothesis for the developmental dyslexias. Journal of Educational Psychology, 91(3), 415-438.

Woodcock, R. W. (1998). Woodcock reading mastery tests-revised. Itasca, IL: Riverside Publishing.

\section{ABOUTTHEAUTHORS}

J. RON NELSON (CEC Chapter \#60), Associate Professor and Co-Director, Center for At-Risk Children's Services, University of Nebraska, Lincoln. scott A. StAge (CEC Chapter \#28), Assistant Professor, Educational Psychology, University of Washington, Seattle. MichaEL H. EPSTEIN (CEC Chapter \#60), William E. Barkley, Professor and Director, Center for At-Risk Children's Services, University of Nebraska, Lincoln. COREY D. PIERCE (CEC Chapter \#186), Assistant Professor, Department of Special Education, Southern Illinois University, Carbondale.

Corey D. Pierce is now at the University of Northern Colorado, Greeley.

Address correspondence to J. Ron Nelson, Center for At-Risk Children's Services, 202 Barkley Center, Lincoln, NE 68583-0732. Phone: 402-4720283 (e-mail: rnelson8@unl.edu)

Preparation of this manuscript was supported in part by a grant from the U.S. Department of Education, Office of Special Education Programs (No. H324D010013). Opinions expressed do not necessarily reflect the position of the U.S. Department of Education, and no endorsement should be inferred.

Manuscript received November 2004; accepted March 2005. 